Research paper

\title{
Ru-dimethyl sulfoxide complexes as catalysts precursors for ROMP of norbornene and ATRP of methyl methacrylate
}

\author{
Patricia Borim ${ }^{a}$, Benedito S. Lima-Neto ${ }^{\mathrm{b}}$, Beatriz E. Goi ${ }^{\mathrm{a}}$, Valdemiro P. Carvalho Jr. ${ }^{\mathrm{a}, *}$ \\ ${ }^{a}$ Faculdade de Ciências e Tecnologia, Universidade Estadual Paulista, CEP 19060-900 Presidente Prudente, SP, Brazil \\ ${ }^{\mathrm{b}}$ Instituto de Química de São Carlos, Universidade de São Paulo, CEP 13560-970 São Carlos, SP, Brazil
}

\section{A R T I C L E I N F O}

\section{Article history:}

Received 7 June 2016

Received in revised form 11 September

2016

Accepted 12 October 2016

Available online 29 October 2016

\section{Keywords:}

Ruthenium

dmso

ATRP

ROMP

Norbornene

Methyl methacrylate

\begin{abstract}
A B S T R A C T
The catalytic activity of the five-coordinated $\left[\mathrm{RuCl}_{2}\left(\mathrm{PPh}_{3}\right)(\mathrm{S} \text {-dmso })_{2}\right]$ complex was investigated for ringopening metathesis polymerization (ROMP) of norbornene (NBE) and for atom transfer radical polymerization (ATRP) of methyl methacrylate (MMA). Syntheses via ROMP of polyNBE were dependent on the ethyl diazoacetate (EDA) amount, used as starting carbene source, monomer concentration, temperature, and reaction time. The best polyNBE yields were obtained at $50^{\circ} \mathrm{C}$ for $120 \mathrm{~min}$ with $[\mathrm{NBE}] /[\mathrm{Ru}]=5000$ in presence of $5 \mu \mathrm{L}$ of EDA. MMA polymerization via ATRP was conducted as a function of time with different ethyl 2-bromoisobutyrate initiator and monomer concentrations. The kinetic data for ATRP show linear increase between MMA conversion and molecular weight. Kinetic studies with the six-coordinated $\left[\mathrm{RuCl}_{2}(\mathrm{~S}-\mathrm{dmso})_{3}(\mathrm{O}-\mathrm{dmso})\right]$ complex also showed an increase in the molecular weight with conversion, but with a marked deviation from theoretical molecular weights. This is consistent with the better control in the polymerization supported by electronic and steric properties of the $\mathrm{PPh}_{3}$ ligand in the title complex
\end{abstract}

(c) 2016 Elsevier B.V. All rights reserved.

\section{Introduction}

Ru-dmso complexes have contributed to the development of new catalysts for a variety of reactions with good catalytic efficiency [1]. In particular, there are few reports in the literature with ruthenium-dmso complexes as catalysts for ring opening metathesis polymerization (ROMP) reactions, and for atom transfer radical polymerization (ATRP) [2,3]. In a previous work, we reported the versatility of $\left[\mathrm{RuCl}_{2}(\mathrm{~S} \text {-dmso })_{3}(\mathrm{O}\right.$-dmso $\left.)\right]$ complex (1) as an efficient catalyst generated in situ for ROMP of NBE [3]. The yield was $62 \%$ $(\mathrm{PDI}=1.64)$ at room temperature for $5 \mathrm{~min}$ and $88 \%(\mathrm{PDI}=1.93)$ at $50{ }^{\circ} \mathrm{C}$ for $30 \mathrm{~min}$, with $[\mathrm{NBE}] /[\mathrm{Ru}]=516$ in $\mathrm{CHCl}_{3}$. The complex was practically inactive when one or two molecules of dmso were replaced by pyridine, imidazole, 2-methyl-imidazole or benzimidazole [3]. This is contrary to many amine-phosphine $\mathrm{Ru}^{\mathrm{II}}$ complexes where the presence of amines enhanced the reactivity in relation to the pure phosphine complexes [4,5]. However, the system with $\mathbf{1}$ is versatile, as it does not require operating conditions with extreme absence of humidity and $\mathrm{O}_{2}$.

In the current work, we describe the reactivity of $\left[\mathrm{RuCl}_{2}\left(\mathrm{PPh}_{3}\right)\right.$ (S-dmso $)_{2}$ ] (2) which comes from the first family of Ru-dmso com-

\footnotetext{
* Corresponding author.

E-mail address: valdemiro@fct.unesp.br (V.P. Carvalho Jr.).
}

plexes [6]. The five-coordinated Ru-dmso compound with $\mathrm{PPh}_{3}$ can be quite interesting for ATRP for several reasons. First, the complex is coordinatively unsaturated because the phosphine steric effect (cone angle of $145^{\circ}$ ). However, this steric hindrance is not so large to avoid the entrance of a substrate to be activated, but it is large enough to provide the departure of the modified substrate. Second, the metal center is electronically unsaturated (16 electrons), which needs an additional ligand, in this case a substrate, to complete the electronic configuration to 18 electrons. In addition, the dmso molecule is able to coordinate to the Ru center by the $\mathrm{O}$ atom (O-dmso as $\pi$-donor ligand) or by the $\mathrm{S}$ atom (S-dmso as $\pi$-acceptor ligand), when the electronic density in the Ru changes, such as O-dmso in low spin $\mathrm{d}^{5} \mathrm{Ru}^{\mathrm{III}}$ ion and S-dmso in low spin $\mathrm{d}^{6} \mathrm{Ru}^{\mathrm{II}}$ ion $[6,7]$. Further, O-dmso occurs when a $\pi$-acceptor ligand is transpositionated at the same plane of the $\mathrm{Ru}^{\mathrm{II}}$ ion, as $\mathrm{S}$-dmso or $\mathrm{CO}$ [7]. Thus, the complex 2 is composed of a combination of a strong bond with the $\pi$-acceptor $\mathrm{PPh}_{3}$ molecule and a relatively versatile bond with dmso. Such combination makes the complex kinetically stable, but it permits an easy activation, once it provides a free vacancy to react via ROMP or via ATRP.

Investigations on new reactions using well-defined catalysts for olefin metathesis and atom transfer radical reactions have been conducted around the world [8-10]. However, there is a stimulating challenge in the search for simpler, cheaper, and perhaps Werner-type systems, in which an active catalytic species could be 
readily generated in-situ, at low cost, upon mixing simple ingredients. In this direction, this paper reports the application of $\mathbf{1}$ and $\mathbf{2}$ for ROMP of NBE and for ATRP of MMA under different conditions of monomer concentration, initiator concentration, and reaction time, as promising dual catalysts (Scheme 1). Ethyl diazoacetate (EDA) was used as starting source of carbene for ROMP and ethyl 2-bromoisobutyrate (EBiB) was used as initiator for ATRP.

\section{Results and discussion}

\subsection{Characterization of $\left[\mathrm{RuCl}_{2}\left(\mathrm{PPh}_{3}\right)(\mathrm{S}-\mathrm{dmso})_{2}\right](\mathbf{2})$}

Additional characterization of $\mathbf{2}$ was necessary to complete the early presented studies [6], to better understand its reactivity in the current purpose.

The precursor 1 was reacted with an equimolar amount of $\mathrm{PPh}_{3}$ in toluene at reflux for $2 \mathrm{~h}$ to obtain the five-coordinated complex $\mathbf{2}$ in good yield, as early suggested [6]. The infrared spectrum of $\mathbf{2}$ displayed two strong bands at 1114 and $1095 \mathrm{~cm}^{-1}$, which are assigned to the $\mathrm{S}=\mathrm{O}$ stretching vibrations. The $\mathrm{Ru}-\mathrm{S}$ vibration occurred at $428 \mathrm{~cm}^{-1}$. These bands now support linkage of dmso to the ruthenium metal center through sulphur, following the literature [6,7]. In addition to other typical bands of the dmso and phosphine, it was also observed bands at 255 and $277 \mathrm{~cm}^{-1}$ attributed to $\mathrm{Ru}-\mathrm{Cl}$ asymmetric and symmetric stretching vibrations, respectively, suggesting two cis-positioned $\mathrm{Cl}^{-}$ligands [11]. From the analysis of the ${ }^{1} \mathrm{H}$ NMR spectrum of 2 , signals at $3.59,3.14$, 2.97, 2.67, 2.62, 2.40 and $2.24 \mathrm{ppm}$ in a ratio of $1: 1: 1: 1: 2: 1: 1$, respectively, are assigned to the methyl groups of the S-bonded dmso, suggesting the presence of two isomers. Further, the ${ }^{31} \mathrm{P}$ $\left\{{ }^{1} \mathrm{H}\right\}$-NMR spectrum of $\mathbf{1}$ shows the appearance of two singlets at 52 and $36 \mathrm{ppm}$, confirming the presence of two geometric isomers. Correlating the NMR data with the FTIR spectrum, which suggested that the two chloride ligands are cis-positioned, a square pyramidal geometry type is assigned to species at $52 \mathrm{ppm}$, with $\mathrm{PPh}_{3}$ at the

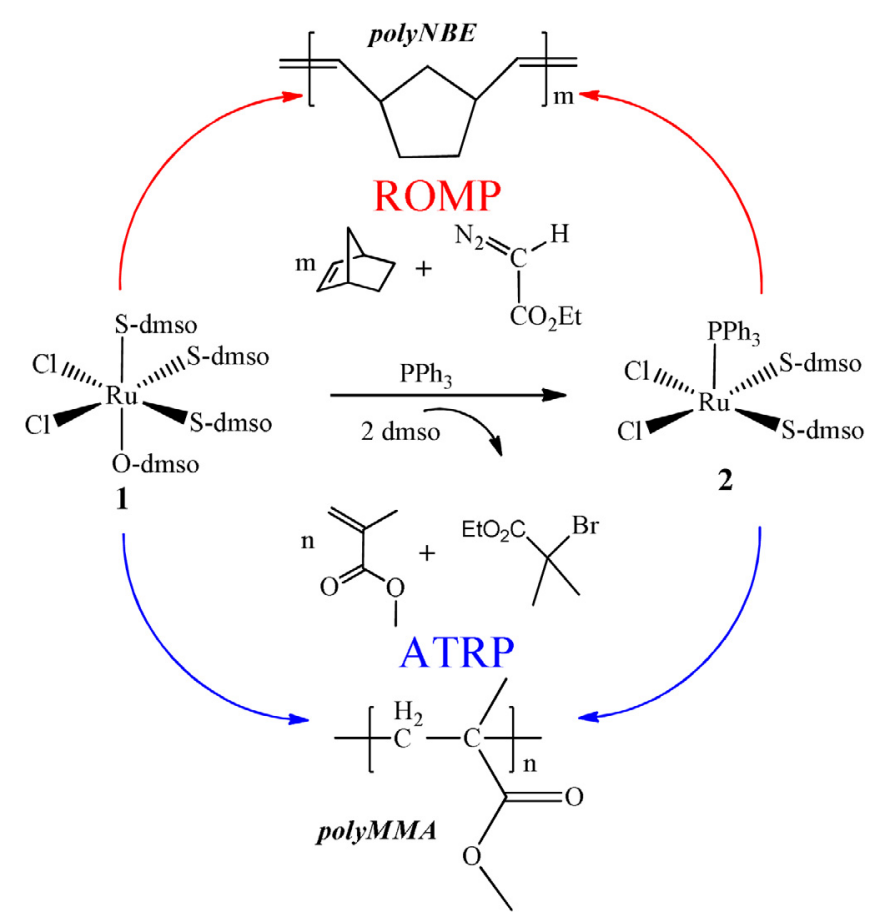

Scheme 1. Illustration of complexes $\mathbf{1}$ and $\mathbf{2}$ as catalysts precursors for ROMP of NBE and ATRP of MMA. axial position. A trigonal bipyramid structure is assigned to the singlet at $36 \mathrm{ppm}$, with two S-dmso in axial axes.

The electronic spectrum of $\mathbf{2}$ presented relatively strong bands below $300 \mathrm{~nm}$, typical of $\mathrm{Ru}^{\mathrm{II}} \rightarrow \mathrm{PPh}_{3}$ and $\mathrm{Ru}^{\mathrm{II}} \rightarrow \mathrm{S}$-dmso charge transfer transitions (Fig. 1) [2,9]. The spectrum did not change for $30 \mathrm{~min}$ at $25^{\circ} \mathrm{C}$, indicating no dissociation of ligands.

The cyclic voltammogram of $\mathbf{2}$ presented a reversible redox process in the potential range between 0.7 and $1.1 \mathrm{~V}$ (Fig. 2), corresponding to the $\mathrm{Ru}^{\mathrm{II}} / \mathrm{Ru}^{\mathrm{III}}$ conversion with $E_{1 / 2}=0.92 \mathrm{~V} v s$. Ag/ $\mathrm{AgCl}$. High redox potential value was associated with the occurrence of $\mathrm{Ru}^{\mathrm{II}} \rightarrow \mathrm{PPh}_{3}$ and $\mathrm{Ru}^{\mathrm{II}} \rightarrow \mathrm{S}$-dmso $\pi$-back-donations that stabilizes the HOMO orbital in the ground state. The complex $\mathbf{1}$ presented $E_{1 / 2}=1.17 \mathrm{~V} v s$. $\mathrm{Ag} / \mathrm{AgCl}$. The decrease in the redox process value indicates higher electronic density in the $\mathbf{2}$ compared with 1.

The electrochemical activity of $\mathbf{2}$ was studied at the scan rates from 50 to $700 \mathrm{mV} \mathrm{s}^{-1}$. The voltammogram curves are typical of reversible processes and, hence, they satisfy the requirement imposed on Nernst systems where the value of electrode potential is independent of the scan rate [12]. For the rate of potential changing equal to $50 \mathrm{mV} \mathrm{s}^{-1}$, the peak-to-peak separation, $\Delta E_{\mathrm{p}}$, is $90 \mathrm{mV}$. Its peak-to-peak separation is comparable to that of the ferroceneferrocenium couple (78 mV), indicating that this $\mathrm{Ru}^{\mathrm{II}} / \mathrm{Ru}^{\mathrm{III}}$ couple is facile to occur and reversible. The $\Delta E_{\mathrm{p}}$ is somewhat larger than the canonical value for ideal Nernstian behaviour $(59 \mathrm{mV})$, indicating some reorganization of the coordination sphere of the ruthenium center during the electron-transfer process. This may reflect preferred coordination geometries for each redox state; $\mathrm{Ru}^{\mathrm{II}}, \mathrm{d}^{6}$ and $\mathrm{Ru}^{\mathrm{III}}, \mathrm{d}^{5}$.

The linear plots of the currents (anodic and cathodic) vs. square root of the potential scan rate (Insert Fig. 2) also indicate reversibility of the redox process. It should be emphasized that redox reversibility in a metal complex is one of the necessary (but not sufficient) conditions for its efficiency in the controlled radical polymerization.

\subsection{Reactivity of complex $\mathbf{2}$ for ROMP}

The ability of $\mathbf{2}$ for generating ruthenium-dmso catalysts in situ was first investigated in the ROMP of NBE. This reaction constitutes a benchmark test to evaluate the activity of catalyst precursors. In a first series of experiments, polymerizations were conducted in

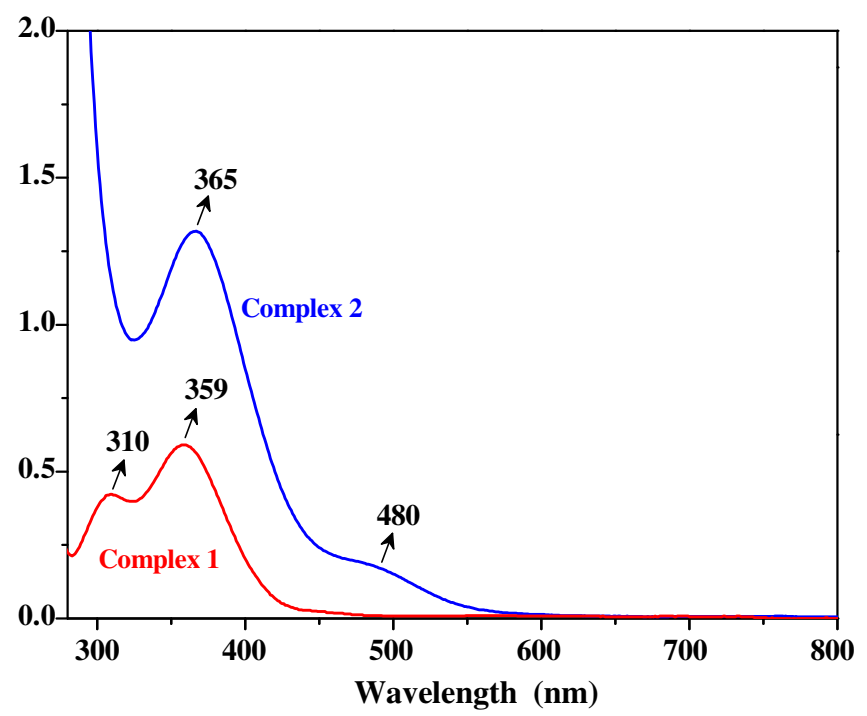

Fig. 1. Electronic spectra of the complexes $\mathbf{1}$ and $\mathbf{2}$ in degassed $\mathrm{CH}_{2} \mathrm{Cl}_{2}$ solution at room temperature $\left([\mathrm{Ru}]=0.1 \mathrm{mmol} \mathrm{L}^{-1}\right)$. 


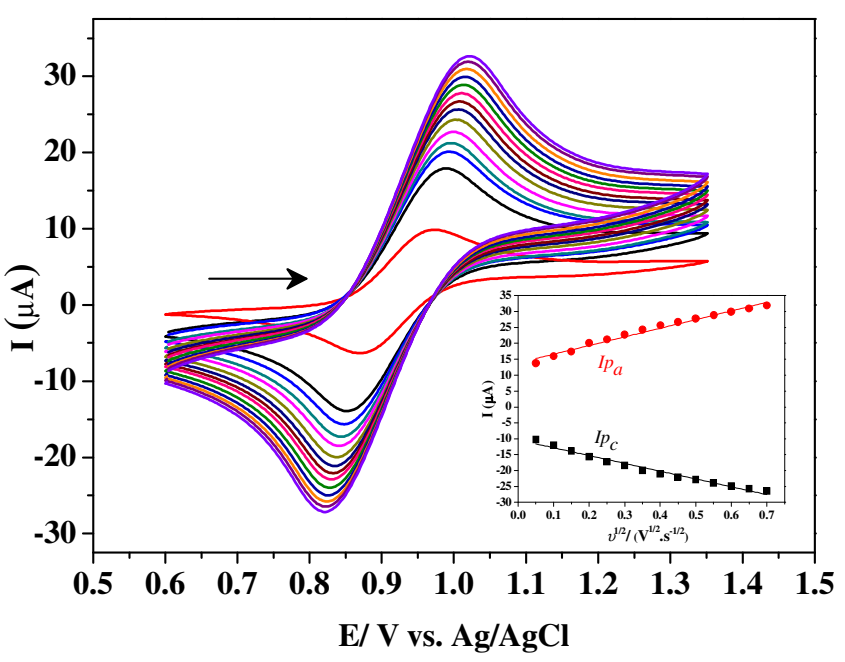

Fig. 2. Cyclic voltammogram of 2 in $\mathrm{CH}_{2} \mathrm{Cl}_{2}$ at $25^{\circ} \mathrm{C}$. [Ru] $=10 \mathrm{mM}$; $\left[n-\mathrm{Bu}_{4} \mathrm{NPF}_{6}\right]$ $=0.1 \mathrm{M}$; a) scanning anodically from $0.6 \mathrm{~V}$ at scan rates of 50,100,150, 200, 250, $300,350,400,450,500,550,600,650$ and $700 \mathrm{mV} \mathrm{s}^{-1}$. Insert: Current (I) of the anodic $\left(I_{\mathrm{pa}}\right)$ and cathodic $\left(I_{\mathrm{pc}}\right)$ processes $v s$. square root of the potential scan rate $(\mathrm{v})$.

$\mathrm{CH}_{2} \mathrm{Cl}_{2}$ at $25^{\circ} \mathrm{C}$ varying the molar ratio of diazo-compound/2 to produce the active species in situ. The effect of the [EDA]/[Ru] molar ratio on the yield of isolated polymer is illustrated in Fig. 3. The catalytic activity is dependent of the EDA concentration, with an increase in the yield values up to $[\mathrm{EDA}] /[\mathrm{Ru}]=28$, followed by a drop for $[\mathrm{EDA}] /[\mathrm{Ru}]>30$, when using $[\mathrm{NBE}] /[\mathrm{Ru}]=5000$ for 5 min at $25^{\circ} \mathrm{C}$; no reaction was observed in absence of EDA. High EDA amount may compete with the monomer over the main reaction [4].

$M_{n}$ values show similar curve profile of the catalytic activity (Fig. 4), which presents an increase in polyNBE molecular weights up to $[\mathrm{EDA}] /[\mathrm{Ru}]=28$, followed by a sharp drop. When the EDA concentration was doubled $([\mathrm{EDA}] /[\mathrm{Ru}]=56)$ probably occurs a competition for Ru ligand sites between NBE and EDA, which affects the ROMP kinetics and, as result, short polymer chains are obtained with high PDI values [4]. Thus, the best values of yield, $\mathrm{M}_{\mathrm{n}}$, and PDI were obtained with $[\mathrm{EDA}] /[\mathrm{Ru}]=28$, suggesting the most satisfactory EDA concentration for the upcoming studies.

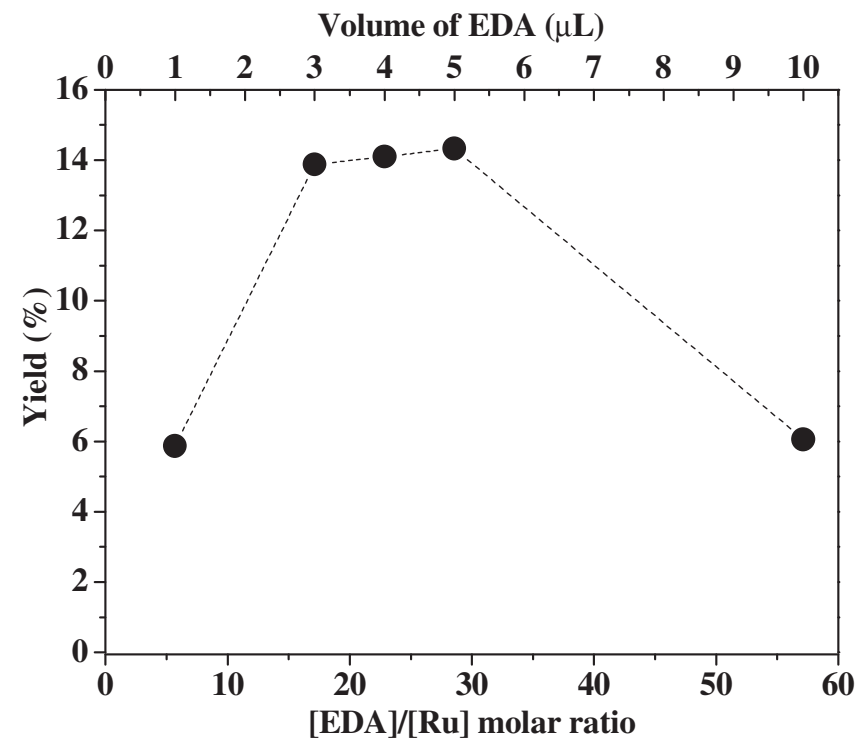

Fig. 3. Dependence of yield on the $[E D A] /[R u]$ molar ratio for ROMP of NBE with 2; $[\mathrm{NBE}] /[\mathrm{Ru}]=5000$ with $1.1 \mu \mathrm{mol}$ of complex in $\mathrm{CH}_{2} \mathrm{Cl}_{2}$ at $25^{\circ} \mathrm{C}$ for $5 \mathrm{~min}$.

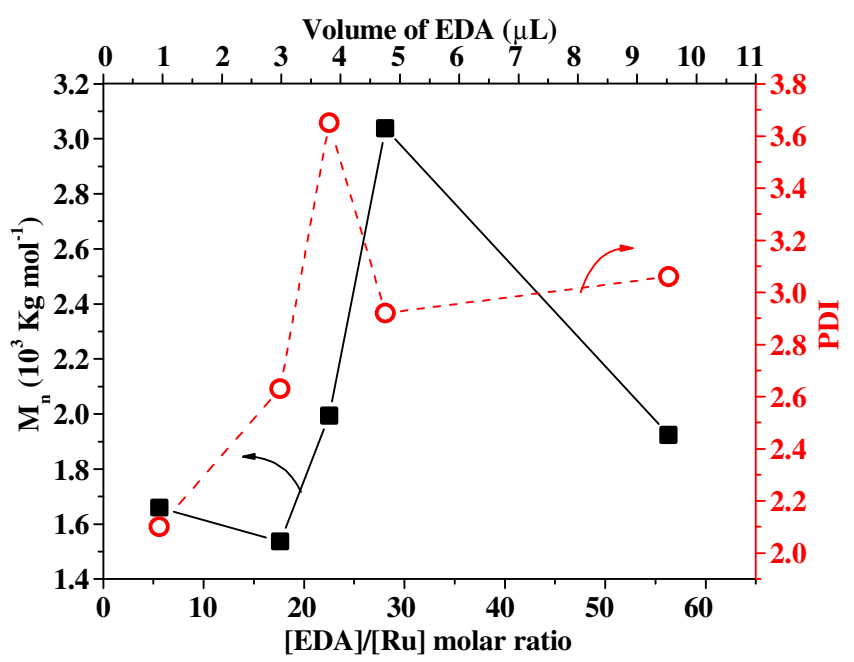

Fig. 4. Dependence of $M_{n}$ and PDI on the [EDA]/[Ru] ratio for ROMP of NBE with 2; $[\mathrm{NBE}] /[\mathrm{Ru}]=5000$ with $1.1 \mu \mathrm{mol}$ of complex in $\mathrm{CH}_{2} \mathrm{Cl}_{2}$ at $25^{\circ} \mathrm{C}$ for $5 \mathrm{~min}$.

The yield increases with NBE concentration when the [NBE]/ [Ru] ratio increases from 1000 to 5000 , at $25^{\circ} \mathrm{C}$ for $5 \mathrm{~min}$, as shown in Fig. 5. Then, it drops after reaching a maximum that can be associated with the formation of gel in the beginning of the reaction, as already observed in the literature [4,5].

The PDI values progressively decreased with the increase in the NBE concentration from $[\mathrm{NBE}] /[\mathrm{Ru}]=2000$, whereas the $\mathrm{M}_{n}$ values increase from $1.8 \times 10^{3}$ to $2.4 \times 10^{3} \mathrm{~kg} \mathrm{~mol}^{-1}$ when the [NBE]/[Ru] ratio was increased from 1000 to 5000 (Fig. 6). An increase of the PDI value from 1000 up to 2000 probably is due to the fact that high Ru concentration with regard to low monomer concentration can produce small chains with different sizes [4,5]. On the other hand, the fact that the PDI values decreased when the amount of NBE was increased in the reaction over $2000-10,000$, suggests that the relationship between the initiation and propagation steps was maintained throughout the investigated range of $[\mathrm{NBE}] /[\mathrm{Ru}]$.

In the experiments as a function of time at 25 or $50{ }^{\circ} \mathrm{C}$ (Fig. 7), the yields increased up to $60 \mathrm{~min}$, following saturation curve profiles, reaching $40 \%$ yield at 25 and $50 \%$ at $50{ }^{\circ} \mathrm{C}$.

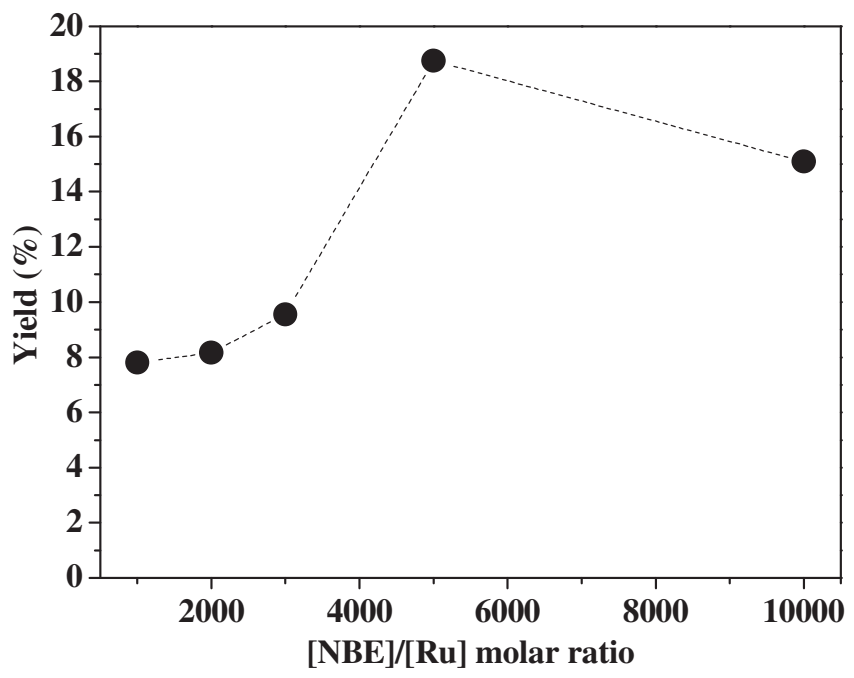

Fig. 5. Dependence of yield on the $[\mathrm{NBE}] /[\mathrm{Ru}]$ ratio for ROMP of NBE with 2; [EDA]/ $[\mathrm{Ru}]=28$ with $1.1 \mu \mathrm{mol}$ of complex in $\mathrm{CH}_{2} \mathrm{Cl}_{2}$ at $25^{\circ} \mathrm{C}$ for $5 \mathrm{~min}$. 


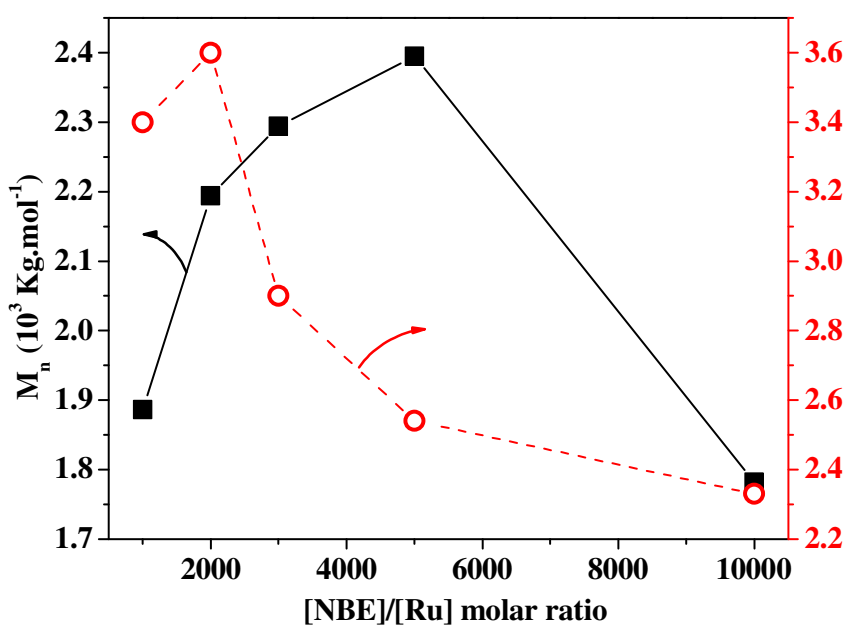

Fig. 6. Dependence of $M_{n}$ and PDI on the [NBE]/[Ru] ratio for ROMP of NBE with 2; $[\mathrm{EDA}] /[\mathrm{Ru}]=28$ with $1.1 \mu \mathrm{mol}$ of complex in $\mathrm{CH}_{2} \mathrm{Cl}_{2}$ at $25^{\circ} \mathrm{C}$ for $5 \mathrm{~min}$.

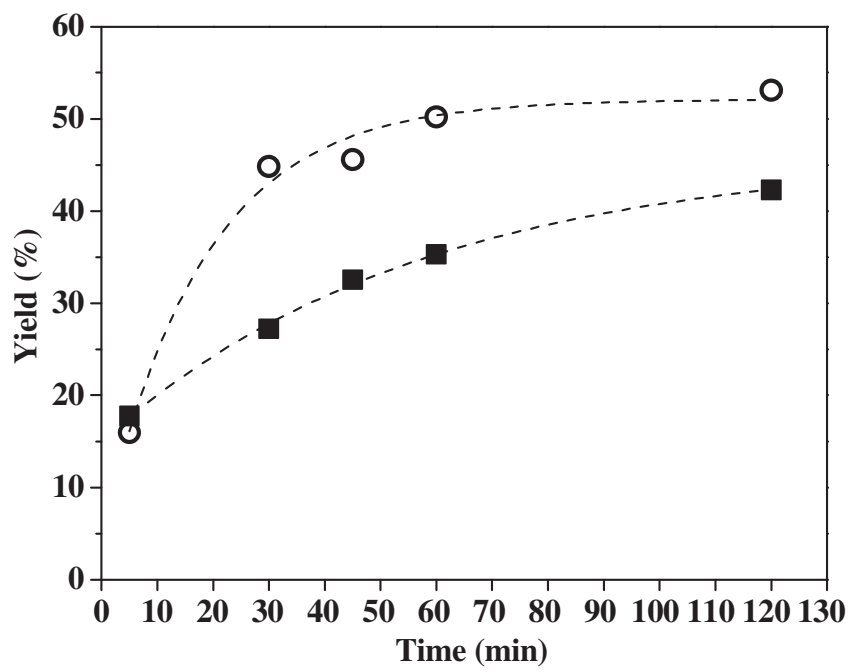

Fig. 7. Dependence of yield on the reaction time for ROMP of NBE with 2; [NBE]/ $[\mathrm{Ru}]=5000$ and $[\mathrm{EDA}] /[\mathrm{Ru}]=28$ with $1.1 \mu \mathrm{mol}$ of complex in $\mathrm{CH}_{2} \mathrm{Cl}_{2}$ at $25(\mathbf{\square})$ and $50^{\circ} \mathrm{C}(\mathrm{O})$.

Experiments in the presence of excess $\mathrm{PPh}_{3}$ did not change the yield at $50{ }^{\circ} \mathrm{C}$ for $60 \mathrm{~min}$ at $[\mathrm{NBE}] /[\mathrm{Ru}]=5000$. In the presence of dmso, the yields were less than $3 \%$ of polyNBE under the same conditions. In the latter case, probably the presence of dmso in solution suppressed the living of a S-dmso ligand, preventing the ROMP initiation. Thus, the polyNBE yields as a function of time at different temperatures can be explained (Fig. 7), where favourable conditions to release dmso at $50{ }^{\circ} \mathrm{C}$ were established, resulting in better yields. Conversely, longer time was necessary for reaching high yields at $25^{\circ} \mathrm{C}$. In this context, a long induction period occurs at $25^{\circ} \mathrm{C}$, whereas a rapid in situ formation of the catalytic species at $50{ }^{\circ} \mathrm{C}$ results in better yields.

Solution of $\mathbf{2}$ monitored by UV-vis spectroscopy in presence of 20-fold excess of $\mathrm{PPh}_{3}$ showed a shifted to shorter wavelengths in the band at $365 \mathrm{~nm}$, whereas no changes in the spectrum was observed with 20-fold excess of DMSO. These experiments support that the ROMP will only occur when the DMSO molecule undergoes discoordination from the metal center (Scheme 2), considering that the polymerization was inhibited in presence of DMSO.

When comparing the results obtained with $\mathbf{1}$ and $\mathbf{2}$ for ROMP of $\mathrm{NBE}$, in general, highest yields occurred with $\mathbf{1}$ at $25^{\circ} \mathrm{C}$ [3]; the best results with 2 were at $50{ }^{\circ} \mathrm{C}$. The lower reactivity of 2 can be associated to low departure of dmso in the induction period. The ${ }^{1} \mathrm{H}$ NMR spectrum of $\mathbf{2}$ in the presence of EDA showed displacements of S-DMSO signals, without appearance of free DMSO signals which suggests that the carbene complex is a six-coordinated species, of type $\left[\mathrm{RuCl}_{2}(\mathrm{~S}-\mathrm{DMSO})_{2}\left(\mathrm{PPh}_{3}\right)\left(=\mathrm{CHCO}_{2} \mathrm{Et}\right)\right]$. No free $\mathrm{PPh}_{3}$ molecule was observed in ${ }^{31} \mathrm{P}$ NMR spectrum. This is in agreement with the fact that $\mathbf{2}$ is an unsaturated 16 electrons species, able to promptly react with EDA to give the corresponding 18-electron derivative complex without S-DMSO or $\mathrm{PPh}_{3}$ displacement (Scheme 2). Consequently, the initiation step is critical to make use of $\mathbf{2}$ as initiators for ROMP, considering that the S-dmso is replaced by a NBE monomer.

The $M_{n}$ values increased gradually from $2.6 \times 10^{3}$ to $3.7 \times 10^{3}$ $\mathrm{kg} \mathrm{mol}^{-1}$ with a tendency to decrease the PDI values when the experiments were conducted as a function of time at $50^{\circ} \mathrm{C}$, with $[\mathrm{NBE}] /[\mathrm{Ru}]=5000$ (Fig. 8). The $\mathrm{M}_{\mathrm{n}}$ values increased up to $60 \mathrm{~min}$ at $25^{\circ} \mathrm{C}$, with the increase in the PDI values, under the same conditions. Considering the improvement in the yields at $50{ }^{\circ} \mathrm{C}$ for long periods, the results from $\mathrm{M}_{\mathrm{n}}$ and PDI support the fact that the temperature provided an improvement in the initiation period.

The ${ }^{13} \mathrm{C}$ NMR spectra of the polyNBE synthesized with 2 were similar to that obtained with $\mathbf{1}$ (Fig. 9). Fractions of the cis structures $\left(\sigma_{\mathrm{c}}\right)$ from the peak areas between 0.4 and $0.5 \mathrm{ppm}$ show that high trans content were obtained. This is probably due to a low steric hindrance in the coordination metal sphere that permit the "twist" of the monomer with more efficiency, favoring the formation of the trans conformation of groups around a $\mathrm{C}=\mathrm{C}$ double bond of the polymer chain. The absence of steric hindrance produced $100 \%$ of trans-polyNBE in ROMP with $\mathrm{RuCl}_{3}$ [13]. From the literature [14,15], polyNBE obtained with Ru-based complexes with high content cis is indicative that the propagating species is rapid. Consequently, a low cis content is indicative of a propagating species with low reactivity. With 2 , the $M_{n}$ and PDI results suggest a slow propagation step. The $r_{\mathrm{c}} \cdot r_{\mathrm{t}}$ values are higher than that one for the $C^{1,4}$ signals, suggesting that the NBE units present a blocky distribution of cis and trans double bonds.

\subsection{Reactivity of complexes $\mathbf{1}$ and $\mathbf{2}$ for ATRP}

The catalytic activities of $\mathbf{1}$ and $\mathbf{2}$ were tested for ATRP of MMA with $\mathrm{EBiB}$ as initiator using different [EBiB]/[Ru] and [MMA]/[Ru] ratios in $\mathrm{CH}_{2} \mathrm{Cl}_{2}$ at $85^{\circ} \mathrm{C}$. Reactions in absence of EBiB failed.

The reaction yields showed favourable dependence on the concentration of $\mathrm{EBiB}$ up to $[\mathrm{EBiB}] /[\mathrm{Ru}]=2$ (Fig. 10), with a decreasing tendency for larger molar rations $([\mathrm{EBiB}] /[\mathrm{Ru}]>2)$, when using $[\mathrm{MMA}] /[\mathrm{Ru}]=3000$ for $17 \mathrm{~h}$ at $85^{\circ} \mathrm{C}$.

The $\mathrm{M}_{\mathrm{n}}$ values also decrease with excess of $\mathrm{EBiB}([\mathrm{EB} i \mathrm{~B}] /[\mathrm{Ru}]$ $>2$; Fig. 11), suggesting an uncontrolled reaction. Probably the active $\mathrm{Ru}(\mathrm{II})$ species can react with the EBiB in excess without abstracting the bromine atom in the initiated polymer chain to continuous the propagation reaction, resulting in polymers with high PDI values. It is interesting to observe that the amount of EBiB affects more the results with $\mathbf{1}$, with strong increase in the PDI values whereas the PDI decrease in the case of $\mathbf{2}$. The ratio [EBiB]/[Ru] $=2$ was selected for the upcoming studies.

When evaluating the effect of the [MMA]/[Ru] ratio in the range between 500 and 3000, the catalytic activity increased and then dropped for [MMA]/[Ru] > 3000 with $\mathbf{1}$ and $\mathbf{2}$ (Fig. 12). This can be associated with the gelation of the solution, affecting the propagation step. The yields appear to be susceptible to the type of catalyst, probably because electronic and steric effects from $\mathrm{PPh}_{3}$ in 2 .

The $M_{n}$ values increased linearly from $1 \times 10^{5}$ to $6 \times 10^{5}$. $\mathrm{g} \mathrm{mol}^{-1}$ with 1 in the range between 500 and 3000 of [MMA]/ [Ru] ratio, but affecting the PDI values (Fig. 13). With 2 , the $\mathrm{M}_{\mathrm{n}}$ values increased from $4 \times 10^{4}$ to $1 \times 10^{5} \mathrm{~g} \mathrm{~mol}^{-1}$ without large effect 


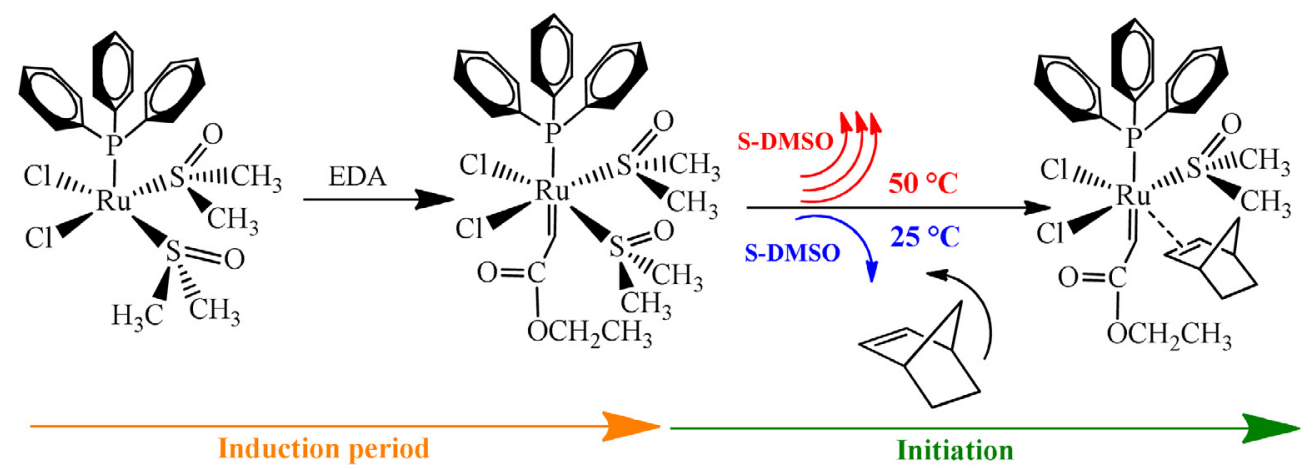

Scheme 2. Illustration of possible reaction steps for ROMP of NBE with 2.

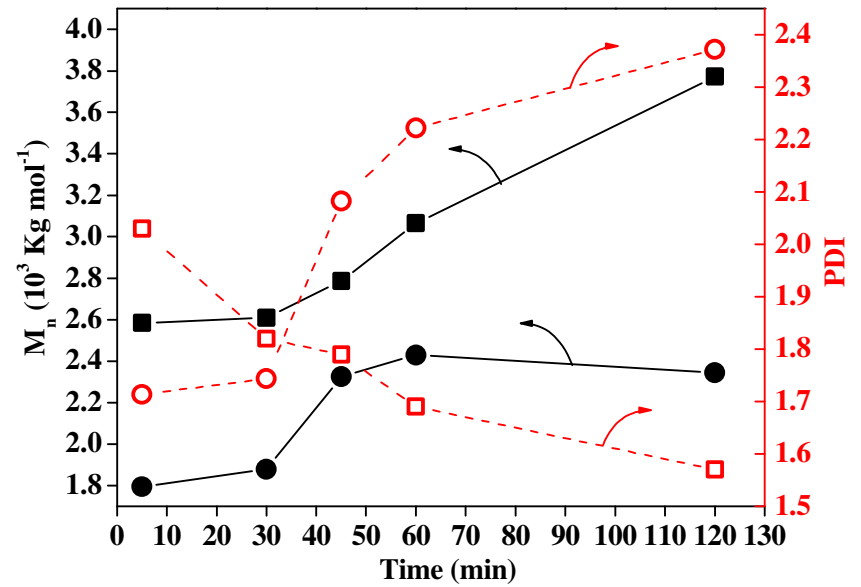

Fig. 8. Dependence of $M_{n}$ and PDI on the reaction time for ROMP of NBE with 2; $[\mathrm{NBE}] /[\mathrm{Ru}]=5000$ and $[\mathrm{EDA}] /[\mathrm{Ru}]=48$ with $1.1 \mu \mathrm{mol}$ of complex in $\mathrm{CH}_{2} \mathrm{Cl}_{2}$ at $25(\bullet$, O) and $50^{\circ} \mathrm{C}(\mathbf{\square}, \square)$.

in PDI values. For runs with large [MMA]/[Ru] ratios, the molecular weights decreased, and the molecular weight distribution are somewhat broader.
Similar increases in the MMA conversions as a function of time were obtained with both catalysts (Fig. 14). The MMA consumption was ca. $5 \%$ higher with 1 than with 2 , with $80 \%$ for 48 h. Linear correlation between $\ln \left([\mathrm{MMA}]_{\mathrm{O}} /[\mathrm{MMA}]\right)$ and time $\left(r^{2}=0.99\right)$ in each case indicates that the concentration of radicals remains constant during the polymerization, which is expected for ATRP [16]. The pseudo-first order rate constants $\left(k_{\text {obs }}\right)$ are $1.31 \times 10^{-5}$ and $1.09 \times 10^{-5} \mathrm{~s}^{-1}$ were determinated for $\mathbf{1}$ and $\mathbf{2}$, respectively.

The Fig. 15 shows that the polyMMA molecular weights increased linearly as a function of the MMA conversions and the PDI values were relatively narrows with both catalysts. When using 1, the molecular weights of polyMMA were much higher than the predicted (for example, $M_{n \text {;exp }}=5.8 \times 10^{5} \mathrm{~g} \mathrm{~mol}^{-1}$ for $21 \%$ of conversion; $\mathrm{M}_{\mathrm{n} ; \mathrm{th}}=6.3 \times 10^{4} \mathrm{~g} \mathrm{~mol}^{-1}$ ) and the molecular weight distributions were somewhat broads $(\mathrm{PDI}=1.43$ ). With 2 , the molecular weights $\left(M_{n ; \exp }=9.9 \times 10^{4} \mathrm{~g} \mathrm{~mol}^{-1}\right.$ for $18 \%$ of conversion $)$ were closer to the calculated values $\left(M_{n ; t h}=5.6 \times 10^{4} \mathrm{~g} \mathrm{~mol}^{-1}\right)$ and the molecular weight distributions were rather narrows (PDI $=1.08)$. These results suggest a polymerization process with $\mathbf{2}$ was more controlled when compared with $\mathbf{1}$.

The polyMMA isolated were characterized by ${ }^{1} \mathrm{H}$ NMR spectroscopy, observing the $\alpha$ - and $\omega$-end groups in the polymer chains (Fig. 16). The signal at $4.18 \mathrm{ppm}$ is assigned to the methylene group of the $\mathrm{EBiB}$ ( $\mathrm{c}$ in Fig. 16), indicating that this compound initiated

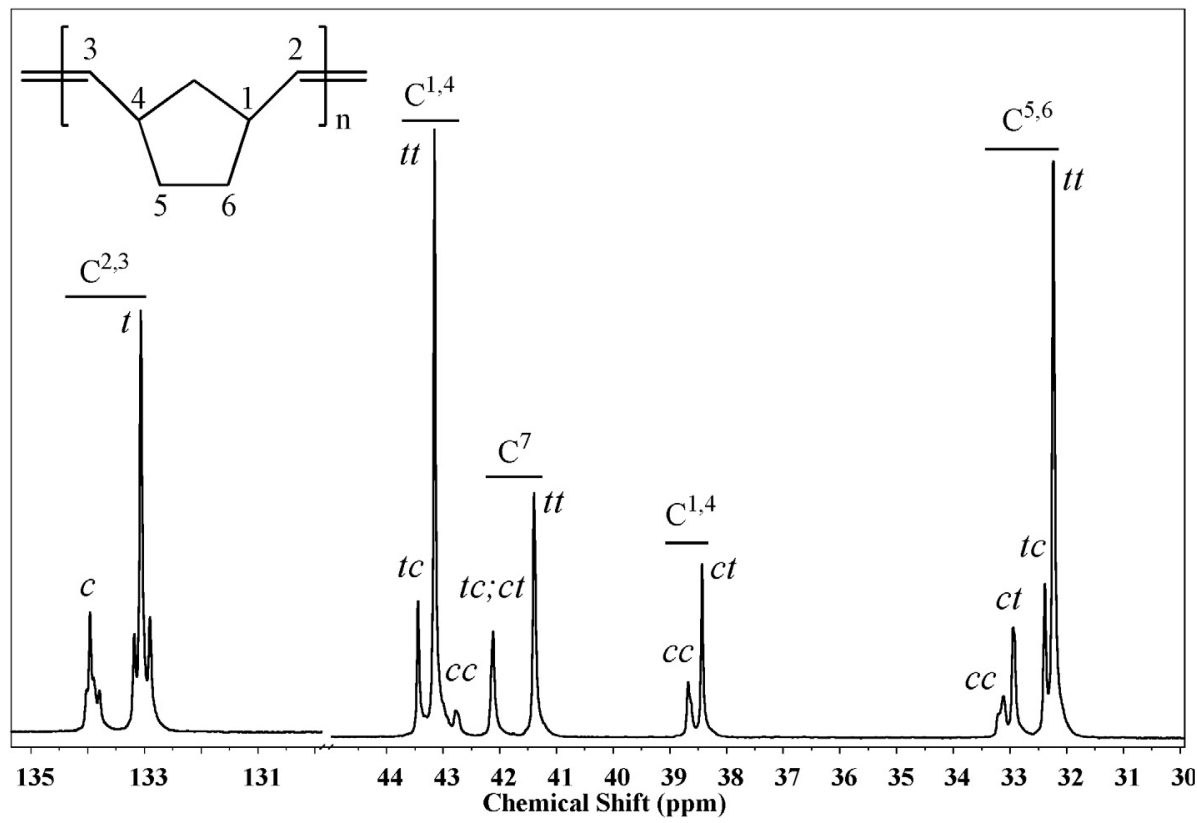

Fig. 9. ${ }^{31} \mathrm{C}$ NMR spectrum of polyNBE obtained with 2 ; $[\mathrm{NBE}] /[\mathrm{EDA}] /[\mathrm{Ru}]=5000 / 48 / 1$ in $\mathrm{CDCl}_{3}$ at $50{ }^{\circ} \mathrm{C}$. 


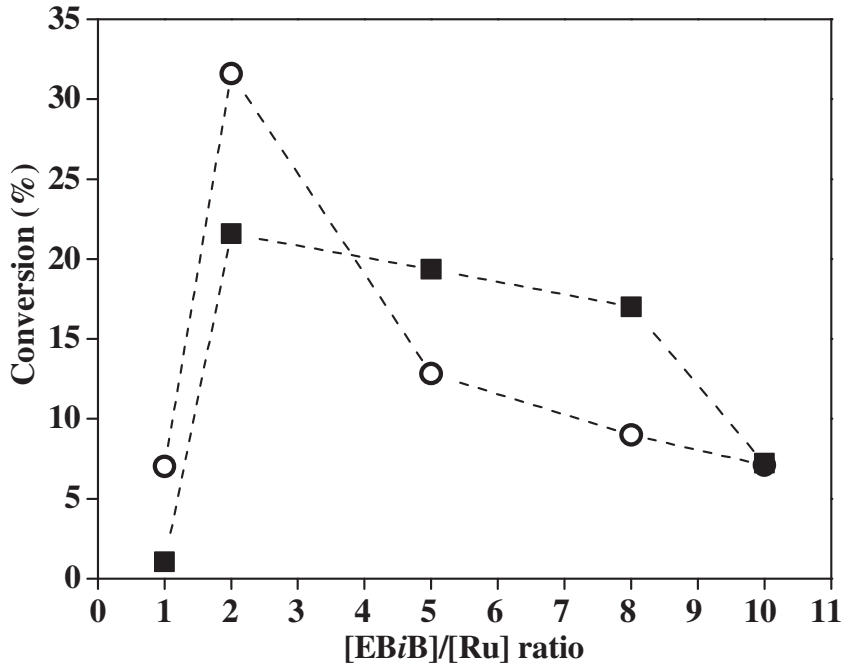

Fig. 10. Dependence of conversion on the $[\mathrm{EBiB}] /[\mathrm{Ru}]$ ratio for ATRP of MMA with 1 (O) and $2(\square)$; [MMA]/[Ru] $=3000$ with $12.3 \mu \mathrm{mol}$ of catalyst in $\mathrm{CH}_{2} \mathrm{Cl}_{2}$ at $85{ }^{\circ} \mathrm{C}$ for $17 \mathrm{~h}$.

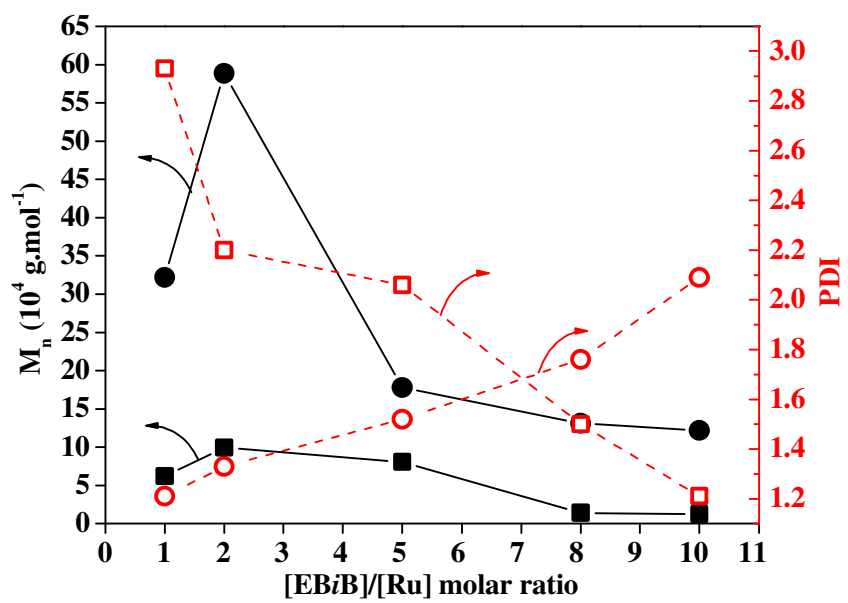

Fig. 11. Dependence of $M_{n}$ and PDI on the [EBiB]/[Ru] ratio for ATRP of MMA with $\mathbf{1}$ $(\bullet, \bigcirc)$ and $2(\square, \square)$; [MMA]/[Ru] $=3000$ with $12.3 \mu \mathrm{mol}$ of complex in $\mathrm{CH}_{2} \mathrm{Cl}_{2}$ at $85^{\circ} \mathrm{C}$ for $17 \mathrm{~h}$.

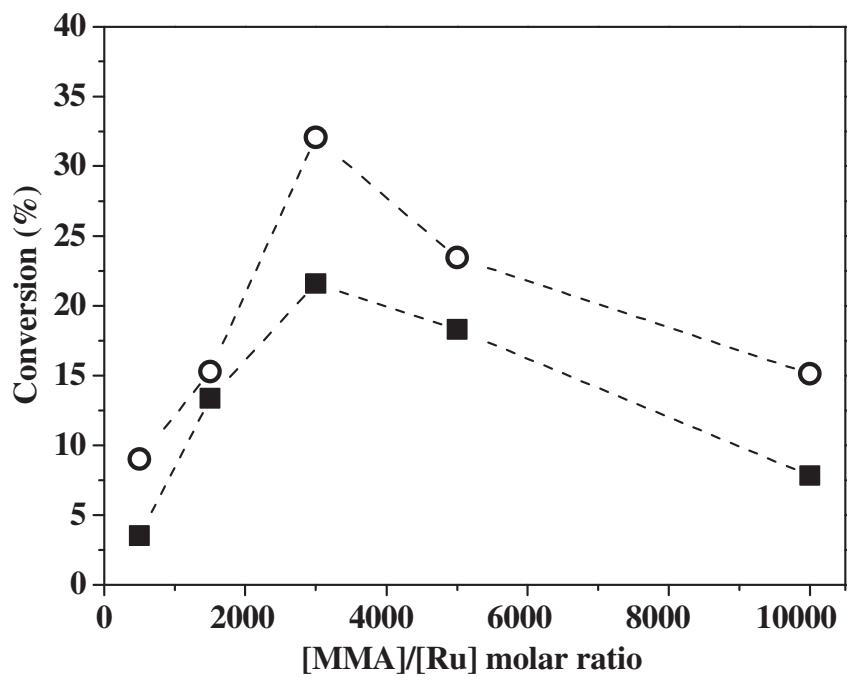

Fig. 12. Dependence of conversion on the $[M M A] /[R u]$ ratio for ATRP of MMA with $1(O)$ and 2 ( $\mathbf{\square})$; [EBiB]/[Ru] = 2 with $12.3 \mu \mathrm{mol}$ of complex in $\mathrm{CH}_{2} \mathrm{Cl}_{2}$ at $85{ }^{\circ} \mathrm{C}$ for $17 \mathrm{~h}$.

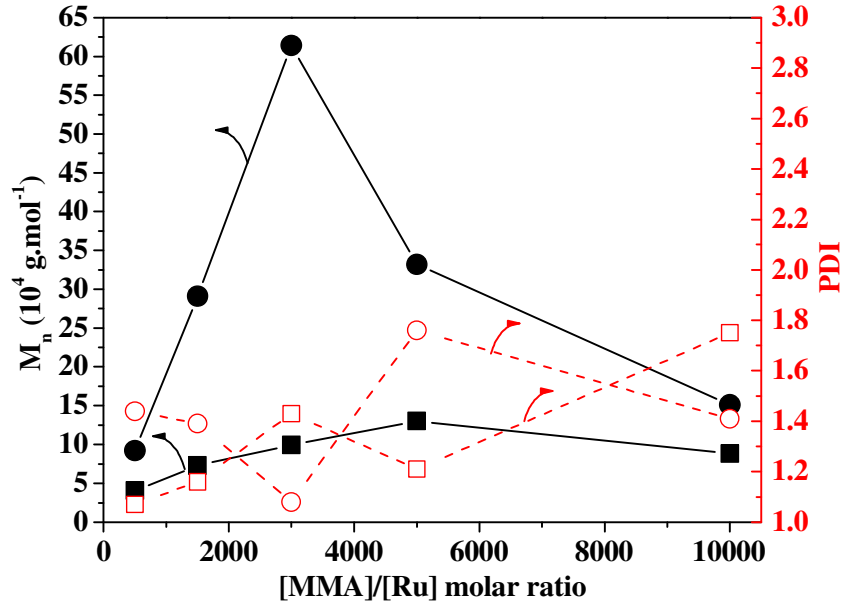

Fig. 13. Dependence of $M_{n}$ and PDI on the [MMA]/[Ru] ratio for ATRP of MMA with $\mathbf{1}(\bullet, O)$ and $\mathbf{2}(\mathbf{\square}, \square) ;[\mathrm{EBiB}] /[\mathrm{Ru}]=2$ with $12.3 \mu \mathrm{mol}$ of complex in $\mathrm{CH}_{2} \mathrm{Cl}_{2}$ at $85{ }^{\circ} \mathrm{C}$ for $17 \mathrm{~h}$.

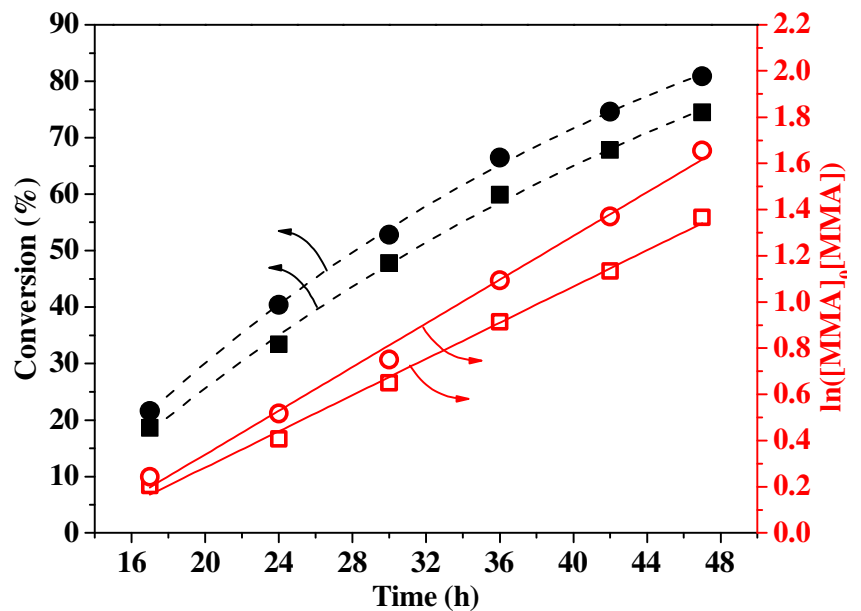

Fig. 14. Dependence of conversion and $\ln \left([\mathrm{MMA}]_{0} /[\mathrm{MMA}]\right)$ on the reaction time for ATRP of MMA with $1(\bullet, O)$ and $2(\boldsymbol{\square}, \square) ;[\mathrm{MMA}] /[\mathrm{EB} i \mathrm{~B}] /[\mathrm{Ru}]=3000 / 2 / 1$ with $12.3 \mu \mathrm{mol}$ of complex in $\mathrm{CH}_{2} \mathrm{Cl}_{2}$ at $85^{\circ} \mathrm{C}$.

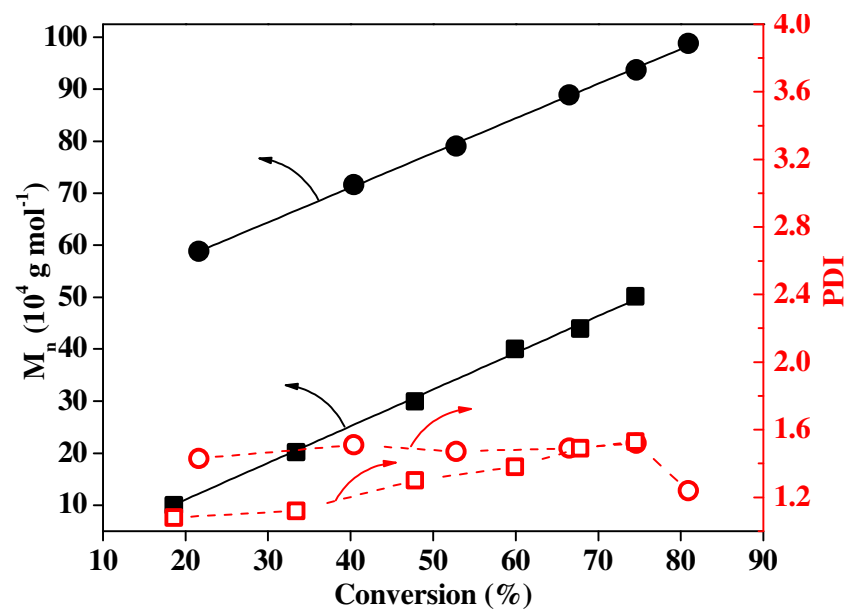

Fig. 15. Dependence of $M_{n}$ and PDI on the conversion for ATRP of MMA with 1 O) and $2(\mathbf{\square}, \square)$; [MMA]/[Ru] = 3000 and $[\mathrm{EBiB}] /[\mathrm{Ru}]=2$ with $12.3 \mu \mathrm{mol}$ of complex in $\mathrm{CH}_{2} \mathrm{Cl}_{2}$ at $85^{\circ} \mathrm{C}$. 


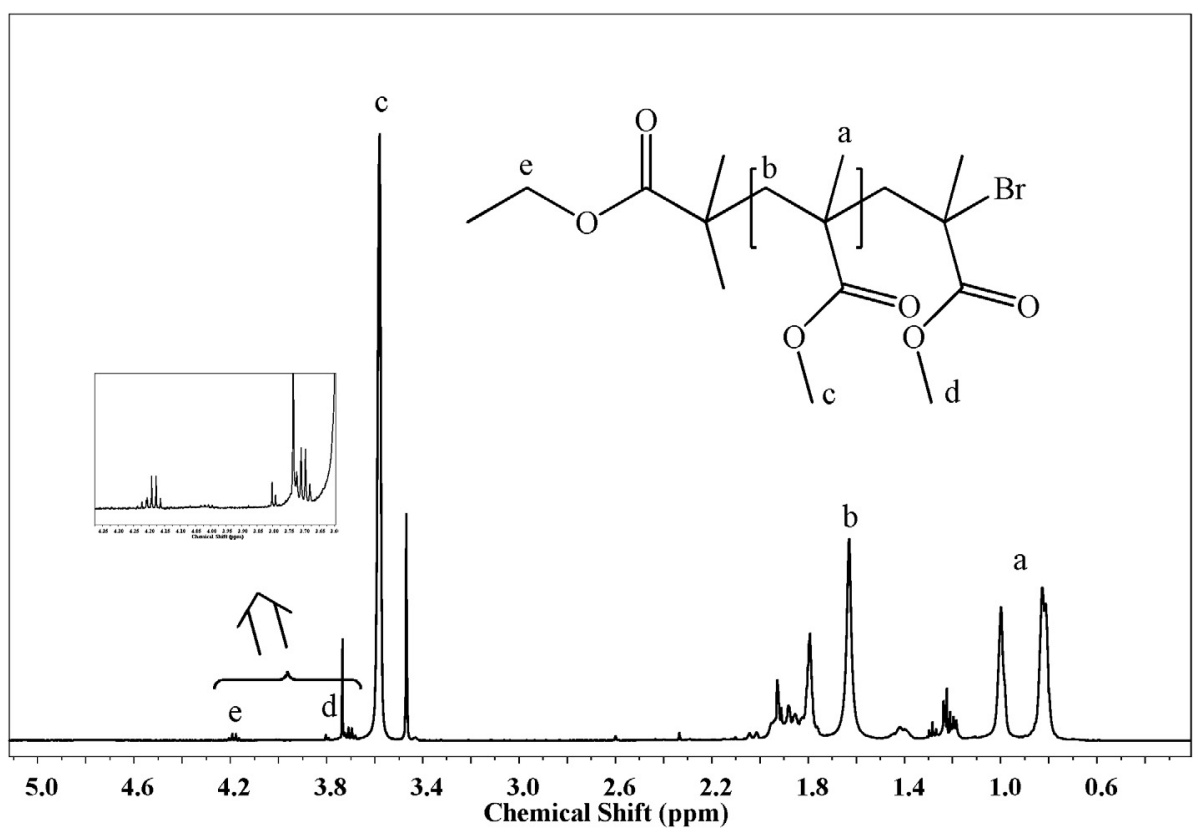

Fig. 16. ${ }^{1} \mathrm{H}$ NMR spectrum of polyMMA obtained with 2; $[\mathrm{MMA}] /[\mathrm{EBiB}] /[\mathrm{Ru}]=3000 / 2 / 1$ in $\mathrm{CDCl}_{3}$ at $85{ }^{\circ} \mathrm{C}$.

the polymer chain. The signal at $3.60 \mathrm{ppm}$ corresponded to the methyl ester groups in polyMMA. The signal at $3.80 \mathrm{ppm}$ is assigned to methyl ester group at the chain-end. This means that the ATRP proceeds via activation of the $\mathrm{C}-\mathrm{Br}$ bond in the $\mathrm{EB} i \mathrm{~B}$ by the $\mathrm{Ru}(\mathrm{II})$ complex, then the $\mathrm{EBiB}$ radical reacts the MMA olefin carbon atom, as proposed by Sawamoto's Research Group [17].

\section{Conclusions}

Ruthenium dimethyl sulfoxide based complexes, $\mathbf{1}$ and 2, were efficiently applied in ROMP and ATRP reactions. The complex 2 showed lower catalytic activity for ROMP of NBE than complex $\mathbf{1}$, which was early studied [3]. This difference in reactivity suggests that the $\mathrm{PPh}_{3}$ molecule participates as ancillary ligand in $\mathbf{2}$, once a free $\mathrm{PPh}_{3}$ dmso-based complex would present similar results. This is associated with the greater stability achieved with the coordination of $\mathrm{PPh}_{3}$ in $\mathbf{2}$ with respect to release of ligands from Ru center, which increased the induction period or the ROMP reaction time. Further, the presence of $\mathrm{PPh}_{3}$ did not inactive the complex as in the case when one or two molecules of dmso were replaced by pyridine, imidazole, 2-methyl-imidazole or benzimidazole [3].

ATRP of MMA were successfully conducted using $\mathbf{1}$ and $\mathbf{2}$ as catalysts. The polymerization rates with both catalysts were similar and a high monomer conversions (ca. 80\%) were achieved for $48 \mathrm{~h}$. The molecular weights of polymers increased linearly with the increase of monomer conversions, indicating controlled polymerization reactions as a function of time. The similarity in the catalytic activity could be questionated for two reasons. First, $\mathbf{2}$ is a five-coordinated complex, with a free vacancy in the axial axis to react promptly with the initiator. Second, $\mathbf{1}$ shows higher oxidation potential compared with $\mathbf{2}$, and then, the halogen atom exchange with the initiator should be more difficult, delaying the beginning of the polymerization. However, it should be considered the $\mathrm{PPh}_{3}$ steric factor and its inert character in $\mathbf{2}$, whereas $\mathbf{1}$ presents a labile O-bonded dmso ligand in the coordination sphere. A fact is that the polyMMA molecular weights obtained with 2 were closer to the theoretical values than those obtained with $\mathbf{1}$, with molecular weight distribution rather narrow.
The complexes $\mathbf{1}$ and $\mathbf{2}$ provide a valuable alternative to preform ruthenium-dmso catalysts for mediating metathetical and radical transformations in polymer chemistry. We conclude that alternative initiators with simple and cheap ancillary ligands can tune the reactivity of catalysts for ROMP of NBE and ATRP of MMA providing practical application towards preparative scale.

\section{Experimental section}

\subsection{General procedures}

All reactions and manipulations were performed under nitrogen atmosphere following standard Schlenk techniques. $\mathrm{CH}_{2} \mathrm{Cl}_{2}$ was dried with $\mathrm{CaCl}_{2}$ overnight, filtered, distilled and degassed by three vacuum-nitrogen cycles under nitrogen before use. Methyl methacrylate (MMA) was washed with $5 \% \mathrm{NaOH}$ solution, dried over anhydrous $\mathrm{MgSO}_{4}$, vacuum distilled from $\mathrm{CaH}_{2}$ and stored under nitrogen at $18{ }^{\circ} \mathrm{C}$ before use. $\mathrm{RuCl}_{3} \cdot \mathrm{xH}_{2} \mathrm{O}, 2,2,6,6$-tetramethyl-1-piperidinoxyl (TEMPO), tetrabutylammoniumhexafluorophosphate $\left(n-\mathrm{Bu}_{4} \mathrm{NPF}_{6}\right)$, norbornene (NBE), ethyl diazoacetate (EDA) and ethyl 2-bromoisobutyrate (EBiB) were used as acquired. The $\left[\mathrm{RuCl}_{2}(\mathrm{~S} \text {-dmso })_{3}(\mathrm{O}-\mathrm{dmso})\right]$ complex was prepared following the literature and its purity was checked by satisfactory elemental analysis and spectroscopic examination $\left({ }^{13} \mathrm{C}\left\{{ }^{1} \mathrm{H}\right\}\right.$ - and ${ }^{1} \mathrm{H}$ NMR; FTIR) [6].

\subsection{Preparation of $\left[\mathrm{RuCl}_{2}\left(\mathrm{PPh}_{3}\right)(\mathrm{S}-\mathrm{dmso})_{2}\right]$ (2) [6]}

In a Schlenk tube under an nitrogen atmosphere, $\mathrm{PPh}_{3}$ $(0.5 \mathrm{mmol} ; 0.13 \mathrm{~g})$ was added to a solution of $\left[\mathrm{RuCl}_{2}(\mathrm{~S}-\mathrm{dmso})_{3}(\mathrm{O}-\right.$ dmso)] ( $0.5 \mathrm{mmol} ; 0.25 \mathrm{~g})$ in degassed toluene $(20 \mathrm{~mL})$. The resulting yellow solution was stirred under reflux for $2 \mathrm{~h}$. The solvent was then distilled under reduced pressure. The solid crude product was dissolved in acetone $(5 \mathrm{~mL})$ and the complex precipitated by the addition of cold ethyl ether. An orange precipitate was then filtered and washed with ethyl ether and then dried in vacuum. Yield: $85 \%(0.26 \mathrm{~g})$. Analytical data for $\mathrm{RuCl}_{2} \mathrm{PS}_{2} \mathrm{O}_{2} \mathrm{C}_{22} \mathrm{H}_{27}$ was 44.67 C, $4.84 \mathrm{H}$ and $10.71 \%$ S; Calcd. 44.75 C, $4.61 \mathrm{H}$ and $10.86 \%$ 
S. FTIR (CsI, $\left.\mathrm{cm}^{-1}\right)$ : 1114, $1095(v \mathrm{~S}=0), 428(v \mathrm{Ru}-\mathrm{S}), 255$ (vas $\mathrm{Ru}-\mathrm{Cl}), 277$ ( $v \mathrm{~s} \mathrm{Ru}-\mathrm{Cl}) .{ }^{1} \mathrm{H}$ NMR $\left(\mathrm{CDCl}_{3}, 298 \mathrm{~K}, 400.13 \mathrm{MHz}, \delta\right)$ : $9.09 \mathrm{ppm}$ (ortho-H, $\mathrm{PPh}_{3}$ ); $7.27 \mathrm{ppm}\left(\right.$ meta- $\mathrm{H}, \mathrm{PPh}_{3}$ ) and 7.76 (para-H, $\left.\mathrm{PPh}_{3}\right), 3.52,3.07,2.90,2.60,2.33,2.28$ and $2.17\left(\mathrm{CH}_{3}, \mathrm{~S}-\right.$ dmso); ${ }^{31} \mathrm{P}\left\{{ }^{1} \mathrm{H}\right\}$ NMR $\left(\mathrm{CDCl}_{3}, 298 \mathrm{~K}, 161.98 \mathrm{MHz}, \delta\right): 52$ and 35 ppm. ESR: no signal was observed.

\subsection{ROMP procedure}

In a typical ROMP experiment, $1.1 \mu \mathrm{mol}$ of complex was dissolved in $\mathrm{CH}_{2} \mathrm{Cl}_{2}(2 \mathrm{~mL})$ with an appropriate amount of monomer (NBE), followed by addition of EDA $(5 \mu \mathrm{L})$. Usually the solution gelled for 1-2 min, but the reaction mixture was stirred for an additional period at 25 or $50^{\circ} \mathrm{C}$ in a silicon oil bath. At room temperature, $5 \mathrm{~mL}$ of methanol was added and the polymer was filtered, washed with methanol and dried in a vacuum oven at $40{ }^{\circ} \mathrm{C}$ up to constant weight. The reported yields are average values from catalytic runs performed at least three times with $10 \%$ error at the most. The isolated polyNBEs were dissolved in THF for GPC data.

\subsection{ATRP procedure}

In a typical ATRP experiment, $12.3 \mu \mathrm{mol}$ of complex was placed in a Schlenk tube containing a magnet bar and capped by a rubber septum. Air was expelled by three vacuum-nitrogen cycles before appropriate amounts of monomer (MMA), initiator (EBiB), and $\mathrm{CH}_{2} \mathrm{Cl}_{2}$ (1 mL) were added. All liquids were handled with dried syringes under nitrogen. The tube was capped under $\mathrm{N}_{2}$ atmosphere using Schlenk techniques, then the reaction mixture was immediately immersed in an oil bath previously heated to the desired temperature. The polymerizations were conducted at $85^{\circ} \mathrm{C}$ for MMA. The samples were removed from the tube after certain time intervals using degassed syringes. The polymerization was stopped when the reaction mixture became very viscous. The reported conversions are average values from catalytic runs performed at least three times.

\subsection{Analyses}

Elemental analyses were performed with a Perkin-Elmer CHNS 2400 at the Elemental Analysis Laboratory of Institute of Chemistry - USP. ESR measurements from solid sample were conducted at $77 \mathrm{~K}$ using a Bruker ESR 300C apparatus (X-band) equipped with a TE102 cavity and an HP 52152A frequency counter. The FTIR spectra in CsI pellets were obtained on a Bomem FTIR MB 102. Electronic spectra were recorded on a Varian model Cary 500 NIR spectrophotometer, using $1 \mathrm{~cm}$ path length quartz cells. The ${ }^{1} \mathrm{H}$ and ${ }^{31} \mathrm{P}\left\{{ }^{1} \mathrm{H}\right\} N M R$ spectra were obtained in $\mathrm{CDCl}_{3}$ at $298 \mathrm{~K}$ on a Bruker DRX-400 spectrometer operating at 400.13 and $161.98 \mathrm{MHz}$, respectively. The obtained chemical shifts were reported in ppm relative to TMS or $85 \% \mathrm{H}_{3} \mathrm{PO}_{4}$. Conversion was determined from the concentration of residual monomer measured by gas chromatography (GC) using a Shimadzu GC-2010 gas chromatograph equipped with a flame ionization detector and a $30 \mathrm{~m}(0.53 \mathrm{~mm}$ I.D., $0.5 \mu \mathrm{m}$ film thickness) SPB-1 Supelco fused silica capillary column. Anisole was added to polymerization and used as an internal standard. Analysis conditions: injector and detector temperature, $250{ }^{\circ} \mathrm{C}$; temperature program, $40^{\circ} \mathrm{C}(4 \mathrm{~min}), 20^{\circ} \mathrm{C} \mathrm{min}^{-1}$ until $200{ }^{\circ} \mathrm{C}, 200^{\circ} \mathrm{C}$ ( $\left.2 \mathrm{~min}\right)$. The molecular weights and the molecular weight distribution of the polymers were determined by gel permeation chromatography using a Shimadzu Prominence LC system equipped with a LC-20AD pump, a DGU-20A5 degasser, a CBM-20A communication module, a CTO-20A oven at $40{ }^{\circ} \mathrm{C}$ and a RID-10A detector equipped with two Shimadzu column (GPC-805: $30 \mathrm{~cm}$, $\emptyset=8.0 \mathrm{~mm}$ ). The retention time was calibrated with standard monodispersed polystyrene using HPLC-grade THF as an eluent at $40{ }^{\circ} \mathrm{C}$ with a flow rate of $1.0 \mathrm{~mL} \mathrm{~min}^{-1}$. Polydispersity Index (PDI) is $M_{w} / M_{n}$. Electrochemical measurements were performed using an Autolab PGSTAT204 potentiostat with a stationary platinum disk and a wire as working and auxiliary electrodes, respectively. The reference electrode was $\mathrm{Ag} / \mathrm{AgCl}$. The measurements were performed at $25{ }^{\circ} \mathrm{C} \pm 0.1$ in $\mathrm{CH}_{2} \mathrm{Cl}_{2}$ with $0.1 \mathrm{~mol} \mathrm{~L}^{-1}$ of $n$ $\mathrm{Bu}_{4} \mathrm{NPF}_{6}$.

\section{Acknowledgements}

The authors are indebted to the financial support from FAPESP ((Process number 2013/10002-0) and Prope (Proc. 2180/002/14$\mathrm{PROPe} / \mathrm{CDC})$.

\section{References}

[1] (a) I. Ferrer, J. Rich, X. Fontrodona, M. Rodriguez, I. Romero, Dalton Trans, 42 (2013) 13461-13469;

(b) L. Gonsalvi, I.W.C.E. Arends, R.A. Sheldon, Chem. Commun. 3 (2002) $202-$ 203 ;

(c) T. Okumura, Y. Morishima, H. Shiozaki, T. Yagyu, Y. Funahashi, T. Wawa, K Jitsukawa, H. Masuda, Bull. Chem. Soc. Jpn. 80 (2007) 507-517;

(d) A.M. Khenkin, L.J.W. Shimon, R. Neumann, Inorg. Chem. 42 (2003) 3331 3339;

(e) R.C. van der Drift, J.W. Sprengers, E. Bouwman, W.P. Mul, H. Kooijman, A.L. Spek, E. Drent, Eur. J. Inorg. Chem. (2002) 2147-2155.

[2] (a) V.P. Carvalho, C.P. Ferraz, B.S. Lima-Neto, Inorg. Chim. Acta 418 (2014) 1-7; (b) I.A. Abdallaoui, D. Semeril, P.H. Dixneuf, J. Mol. Catal. A: Chem. 182 (2002) 577-583;

(c) J.A. Camerano, A.S. Rodrigues, F. Rominger, H. Wadepohl, L.H. Gade, J. Organomet. Chem. 696 (2011) 1425-1431.

[3] S.A.A. Santana, V.P. Carvalho Jr., B.S. Lima-Neto, J. Braz. Chem. Soc. 21 (2010) 279-287.

[4] (a) V.P. Carvalho, C.P. Ferraz, B.S. Lima-Neto, J. Mol. Catal. A: Chem. 333 (2010) 46-53;

(b) H.K. Chaves, C.P. Ferraz, V.P. Carvalho, B.S. Lima-Neto, J. Mol. Catal. A: Chem. 385 (2014) 46-53;

(c) L.R. Fonseca, E.S.P. Nascimento, J.L.S. Sa, B.S. Lima-Neto, New J. Chem. 39 (2015) 4063-4069;

(d) J.M.E. Matos, B.S. Lima-Neto, J. Mol. Catal. A: Chem. 259 (2006) 286-291.

[5] V.P. Carvalho, C.P. Ferraz, B.S. Lima-Neto, Eur. Polym. J. 48 (2012) 341-349.

[6] I.P. Evans, A. Spencer, G. Wilkinso, J. Chem. Soc. Dalton Trans. (1973) 204-209.

[7] (a) E. Alessio, Chem. Rev. 104 (2004) 4203-4242;

(b) M. Calligaris, O. Carugo, Chem. Rev. 153 (1996) 83-154.

[8] (a) K. Matyjaszewski, Macromolecules 45 (2012) 4015-4039;

(b) D.J. Siegwart, J. Kwon Oh, K. Matyjaszewski, Prog. Polym. Sci. 37 (2012) 1837;

(c) V. Dragutan, I. Dragutan, L. Delaude, A. Demonceau, Coord. Chem. Rev. 251 (2007) 765-794:

(d) A. Demonceau, L. Delaude, Dalton Trans. 41 (2012) 9257-9268;

(e) J. Vougioukalakis, R.H. Grubbs, Chem. Rev. 110 (2010) 1746-1787;

(f) R.R. Schrock, Dalton Trans. 40 (2011) 7484-7495;

(g) B.D. Clercq, F. Verpoort, J. Mol. Catal. A: Chem. 180 (2002) 67-76;

(h) B.D. Clercq, F. Verpoort, Macromelocules 35 (2002) 8943-8947.

[9] M.K. Smith, J.A. Gibson, C.G. Young, J.A. Broomhead, P.C. Junk, F.R. Keene, Eur. J. Inorg. Chem. 6 (2000) 1365-1370.

[10] C.W. Bielawski, R.H. Grubbs, Prog. Polym. Sci. 32 (2007) 1-29.

[11] K. Nakamoto, Infrared and Raman Spectra of Inorganic and Coordination Compounds: Applications in Coordination, Organometallic, and Bioinorganic Chemistry, John Wiley \& Sons, Canada, 1997.

[12] (a) D.K. Gosser, Cyclic Voltammetry. Simulation and Analysis of Reaction Mechanisms, 1 ed., Wiley-VCH, 1993, pp. 72-75;

(b) C.G. Zoski, C.R. Luman, J.L. Fernandez, A.J. Bard, Anal. Chem. 79 (2007) 4957-4966.

[13] E.M.D. Gillan, J.G. Hamilton, O.N.D. Mackey, J.J. Rooney, J. Mol. Catal. 46 (1988) 359-371.

[14] M.M. Gallagher, A.D. Rooney, J.J. Rooney, J. Mol. Catal. A: Chem. 303 (2009) 7883.

[15] V. Amir-Ebrahimi, J.J. Rooney, J. Mol. Catal. A: Chem. 208 (2004) 115-121.

[16] (a) S.D.A. Richel, C. Cremasco, L. Delaude, A. Demonceau, A.F. Noels, Tetrahedron Lett. 44 (2003) 6011-6015;

(b) J. Baraut, A. Massard, F. Chotard, E. Bodio, M. Picquet, P. Richard, Y. Borguet, F. Nicks, A. Demonceau, P. Le Gendre, Eur. J. Inorg. Chem. (2015) 2671-2682; (c) A.D.F. Simal, A.F. Noels, Comm. (1999) 538-540.

[17] H. Uegaki, Y. Kotani, M. Kamigaito, M. Sawamoto, Macromolecules 30 (1997) 2249-2253. 